\title{
ARTÍCULOS
}

\section{Pedagogía Virtual. Nueva propuesta para el diseño de libros de texto gratuito}

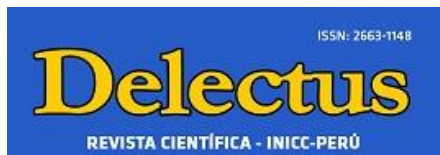

\author{
Virtual Pedagogy. New proposal for a free textbook design \\ Rentería Castro, Enrique
}

Enrique Rentería Castro

erenteriac@gmail.com

Director General del Instituto de Evaluación y Desarrollo Educativo, Presidente Club Unesco Compse, México

Delectus

Instituto Nacional de Investigación y Capacitación Continua, Perú ISSN-e: 2663-1148

Periodicidad: Semestral

núm. 2, 2021

publicaciones.iniccperu@gmail.com

Recepción: 2021

Aprobación: 2021

Publicación: 01 Julio 2021

Esta licencia permite a otros entremezclar, ajustar y construir a partir de su obra con fines no comerciales, y aunque en sus nuevas creaciones deban reconocerle su autoría y no puedan ser utilizadas de manera comercial, no tienen que estar bajo una licencia con los mismos términos.

\section{(c) (9)}

Esta obra está bajo una Licencia Creative Commons AtribuciónNoComercial 4.0 Internacional.
Resumen: El propósito de este artículo consiste en dar fundamentos para el uso del hipertexto en los libros de texto gratuito, como respuesta a la propuesta del rediseño a los contenidos e imagen de los libros de educación básica. Para este fin se considera importante hacer la revisión histórica del uso de libro en educación primaria, en donde destacan más los elementos de orden político e ideológico en contraposición a los intereses de orden pedagógico y didáctico. Consideraremos como inicio el año 1921 con la impresión de las lecturas clásicas, periodo donde no es obligatorio usar libro único de texto; revisaremos la obligatoriedad y gratuidad del libro de texto, concluyendo con el análisis de los libros en los años 2010 a 2020, proponiendo el uso de los libros de texto en formato digital sustentando la visión predictiva de Marshall McLuhan con la descripción de los medios como extensión del hombre.

Palabras clave: libro texto gratuito; reformas educativas; lectura; escritura.

Abstract: The purpose of this article is to provide a basis for the use of hypertext in free textbooks, in response to the proposal to redesign the content and images of basic education books. For this purpose, it is considered important to make the historical review of the use of books in primary education, where the elements of a political and ideological order stand out more as opposed to the interests of a pedagogical and didactic order. We will consider the year 1921 as the beginning with the printing of the classical readings, a period where it is not mandatory to use a single textbook; We will review the obligatory and free nature of the textbook, concluding with the analysis of the books in the years 2010 to 2020, proposing the use of textbooks in digital format supporting the predictive vision of Marshall McLuhan with the description of the media as an extension of man.

Keywords: free textbook; educational reforms; reading; writing.

\section{INTRODUCCIÓN}

La Dirección General de Materiales Educativos de México ha iniciado un proyecto denominado rediseño de los contenidos del libro de texto de educación básica, la metodología que propone consiste en trascender de la escritura monológica a las implicaciones políticas y pedagógicas del diseño de materiales educativos desde un carácter dialógico, generando una normativa para 
acercarse al discurso de polifonía al interior de cada texto; respondieron a la convocatoria dos mil 650 participantes, de los cuales 250 son pasantes, mil 32 tienen licenciatura, mil 82 tienen estudio de maestría, 283 tienen estudios de doctorado y 3 con estudios postdoctorales; quienes trabajarán en conjunto para aportar reflexiones filosóficas, lingüísticas y estéticas que permitan que cada palabra, cada texto se construya sobre los conceptos de dialogismo y alteridad en el pensamiento de Mijail Bajtín; los cuales se centran en una conceptualización del acto con el ser, la responsabilidad, la conciencia con el entorno social y político en contraposición axiológica entre el yo y el otro, que describen el mundo real del acto ético no como algo abstracto, sino como momentos de estructuración y disposición concreta definidos como: “yo-para-mí, otro-para-mí y yo-para-otro. Todos los valores de la vida real y de la cultura se distribuyen en torno a estos puntos existenciales principales del mundo real del acto ético: los valores científicos, los estéticos, los políticos (los éticos y los sociales inclusive) y, finalmente, los religiosos. Todos los valores espacio-temporales y de contenido semántico se estructuran en torno a estos momentos centrales emocionales y volitivos: yo, otro, yo-para otro" (Bajtín, 1997, p.61). Para el filólogo ruso, el objetivo de las ciencias humanas es el ser expresivo y parlante, su realidad es el texto y lo significativo es lo que se habla. La unidad del esquema bajtiniano está delimitada por la realidad ética, estética y cognoscitiva que comporta una determinada obra. El acto, consustancial a cada una de las tres instancias, pertenece al ámbito intelectivo y responsable del ser humano, oscilante entre el lenguaje de una obra literaria (léase como libro de texto) y el lenguaje externo que busca sentidos.

Interesante propuesta que motiva nuestro interés por hacer una breve revisión de los principales momentos históricos en la elaboración y diseño de los libros de texto gratuitos en México, iniciando por la obra de Vasconcelos (1922), quién define a la lectura como elemento fundamental para formar seres críticos y propositivos.

\section{DESARROLLO}

\section{Vasconcelos, la cruzada de los libros y la formación de una nueva cultura mexicana}

Desde la creación de la Comisión Nacional de Libro de Texto Gratuito se ha interrumpido la afluencia generalizada de obras y autores preocupados por generar lectores, la autoridad educativa ha considerado que los libros de texto para educación básica son gratuitos y obligatorios, pero antes de mencionar los sucesos históricos que dan muestra de este hecho, es importante reconocer los alcances en la propuesta de José Vasconcelos fundador de bibliotecas, editor de libros clásicos y fundador de la misma Secretaría de Educación Pública.

Durante los años 20 (siglo pasado) la industria editorial mexicana tenía momentos de mucha inestabilidad, aunado a los años donde la crisis económica generada por el movimiento de la Revolución Mexicana, no existían ventas, además no existía un mercado potencial de lectores. Las bibliotecas eran pocas y la mayoría funcionaba más como bodegas o depósitos de libros que como lugares para promover la lectura. Vasconcelos concibe que lo más importante en un país es la lectura, para lograrlo era necesario contar con libros para leer y con centros de lectura; para él resulta de mayor interés la biblioteca práctica donde hubiese libros de información y aprendizaje que coleccionen incunables y libros raros. Por tanto, la construcción de bibliotecas en cada municipio, fue prioritario, pero resultaba necesario tener bibliotecas grandes en la ciudad de México. Vasconcelos estaba consciente de la importancia de albergar en la Biblioteca Nacional en su local de la antigua Iglesia de San Agustín donde pese a todo esfuerzo el proyecto no estaba al alcance de los recursos del erario por lo que la Biblioteca Nacional fue un proyecto frustrado y hubo de continuar la sede en las calles de Uruguay e Isabel la Católica hasta 1979 que es trasladada a la Universidad Nacional Autónoma de México. 
Vasconcelos creó dos bibliotecas importantes la Iberoamericana especializadas en obras relativas a la cultura, historia y realidad latinoamericana alojada a un costado de la Secretaría y la otra fue la biblioteca Miguel Cervantes Saavedra dedicada a la literatura; esta se albergó en un edificio nuevo en calle San Fernando esquina con Héroes, colonia Guerrero. Para Vasconcelos la lectura no solo se realiza en establecimientos públicos la utopía de un hombre culto de un buen lector es que todas las casas de los ciudadanos deben tener libros y particularmente aquellos cuyo mensaje y contenido fuesen universales, indudablemente las escuelas de educación primaria fueron beneficiadas por la edición de libros clásicos, a pesar del ataque de las editoriales que no comprendían porqué se obligaba a que los niños leyeran libros clásicos, que esta era una competencia desleal de los talleres gráficos de la nación, hacia la industria editorial. José Vasconcelos enfrentó el ataque de sus detractores y siempre les insistía que un pueblo lector demandaría más obras y ellos serían beneficiados al existir mayor consumo de libros.

Vasconcelos publicó obras fundamentales de la cultura universal y al mismo tiempo libros de índole técnica que sirviesen de auxiliares a los docentes y para elementos de auto aprendizaje se procedió por lo mismo a editar los clásicos de la lectura de la literatura universal antiguos y modernos además de obras auxiliares didácticas entre los libros podemos mencionar La Ilíada, La Odisea, Las Tragedias de Esquilo Sófocles y Eurípides; tres volúmenes de Diálogos de Platón, las Enéadas de Plotino, los Evangelios, literatura hindú, textos del budismo, Fausto de Goethe, La Divina Comedia, libros como la Historia de la antigüedad de Justo Sierra y los Principios críticos sobre el virreinato de Agustín Rivera y San Román(Matute, 1982, pp. 177-181).

Cada uno de los libros tenía un pasaje introductorio tomado de algún texto de literatura o de filosofía y en ocasiones un glosario de términos de comprensión difícil. Una de las obras trascendentales fue la creación en marzo de 1921 la revista El Maestro, su función consistió en completar el trabajo de los establecimientos universitarios y escolares, ampliar los horizontes de obreros y campesinos, estimular el estudio de profesionistas y escolares, y animar con sugerencias prácticas a los industriales y explotadores de la tierra. Vasconcelos elaboró una ideología educativa con la que pretendía refundar México, obligando a la sociedad mexicana a reflexionar sobre su propia esencia para transformarse, agrupando tres elementos sustantivos del saber: la escuela, la biblioteca y las bellas artes (Leines, 2005).

Otras de las antologías de gran importancia son: Lecturas clásicas para mujeres con la participación de Gabriela Mistral y Lecturas clásicas para niños, obra reimpresa por la Comisión Nacional de Libro de Texto Gratuito en 1971.

Vasconcelos decretó que no habría más libro de lectura que el de primer año con el que los niños aprendieran a leer y escribir. Editó el Libro nacional de lectura, con un tiraje de 10,000 ejemplares. Posteriormente los niños tendrían acceso a la literatura general con las Lecturas clásicas para niños y las Lecturas para mujeres, compiladas por Gabriela Mistral, las obras de Torres Quintero, Adelante de Daniel Delgadillo, y Rosas de la Infancia y Corazón. Entre los libros de texto que se reeditaron se encontraban dos de Justo Sierra: Historia Universal e Historia Patria cuya edición llegó a los 30000 ejemplares. Una contribución importante fue El Libro y el Pueblo, publicación periódica que informaba sobre la producción nacional y extranjera (Vasconcelos, 1922, pp. 40-53).

En el Gobierno del presidente Calles se pensó que la elección de un libro de texto oficial era una imposición y se limitó la producción de textos. Circularon además de los métodos para alfabetizar, El libro del campesino, y Corazón de Edmundo D'Amicis. Dos años después comenzaron a editarse libros destinados específicamente al medio rural. Libros como Vidas campesinas o El Sembrador, que divulga las experiencias, intereses y necesidades de los habitantes del campo, promoviendo los beneficios de una vida sana e higiénica y exaltaron valores como la cooperación, la diligencia y la 
honestidad; así como denunciaron la explotación del campesino y su miseria, como en Fermín. Con estos libros se incluyó en la literatura oficial una cierta dosis de crítica social que fue aumentando en los siguientes años (Loyo, 1988, pp. 268,269).

\section{Las reformas educativas y los libros de texto}

El libro usado como instrumento democratizador y libertador ha sido referido por diferentes autores hasta los comienzos del siglo XX, Celestin Freinet, como ejemplo, del uso de la imprenta en la escuela, con fines de lectura reflexiva, crítica y propositiva de investigaciones que impacten en su entorno. En muchos países de América Latina es hasta la segunda mitad del siglo XX, cuando se imprimen libros de texto para la educación primaria, tema que ha sido polémico para el caso de México en cuatro periodos específicos, los libros de texto de la educación socialista 1937, los libros de texto durante la creación en 1959 del Comisión Nacional de Libros de Texto Gratuitos, sus primeras ediciones durante los años 60; un tercer periodo durante la reforma educativa en los años 1970 cuyos libros de texto tuvieron vigencia hasta el año 1992, donde aparece una nueva propuesta para el diseño de los libros de texto. A continuación, mencionaremos el sustento pedagógico e ideológico de los libros de texto gratuito en dichos períodos.

La política educativa nacional que se organiza y difunde en dispositivos públicos y obligatorios como los libros de texto gratuitos constituye un indicativo importante para comprender no solo los cambios en las ideas oficiales sobre la comunidad nacional, sino los giros en los proyectos de integración sustentados en la legitimación y la justificación de la autoridad del orden social que se instituye a través de la política educativa (Vargas, 2011, p. 490).

La reforma educativa de 1934 que modificó el Artículo $3^{\circ}$ constitucional y estableció la educación socialista en México. Estas políticas educativas aparecen en los textos escolares más nítidamente que en otros periodos de la historia de la educación mexicana, pues significó, al menos en los propósitos establecidos, una ruptura con las políticas educativas anteriores; de ahí el cambio que se manifiesta de manera evidente y abierta en los contenidos de los libros escolares controlados por el Gobierno. En los textos escolares cardenistas aparecen la ciudad y el campo, los campesinos y los obreros, los niños campesinos y los niños citadinos, las madres de estos niños, todos con la misma tarea encomendada: cambiar sus formas de pensamiento para luchar por la transformación de la sociedad mexicana. A estas nuevas políticas y reformas educativas se ajustaron los autores de los libros de texto.

Gonzalo Vázquez Vela, segundo secretario de Educación del gabinete cardenista, expresaba de los profesores que escriben libros:

Una de las equivocaciones más ingenuas y corrientes es la de suponer que los mejores maestros son aquellos que han escrito libros llenos de erudición pedagógica. No, el maestro, el verdadero educador, el que necesita y ha servido a la Revolución, es un hombre predominantemente práctico, aquel que consagra su vida a la verdadera acción educativa, aquel que no se detiene en la acción puramente escolar, sino que la lleva extramuros al taller o al campo, que defiende la parcela de los campesinos, el salario de los trabajadores, en fin, aquel que hace de sus educandos: niños, jóvenes o adultos, sujetos y agentes eficaces de propaganda a favor de la sanidad, trabajo y movilización en cada uno de los centros del ambiente que los circunda" (El Nacional, Mayo 17, 1936, citado por Montes de Oca, 2007).

El Nacional se dedicó a publicar libros de texto y de pedagogía para reforzar la nueva educación en México. Se publicaron libros como Cartas a los maestros rurales de León Díaz Cárdenas, El método de proyectos en las escuelas rurales, de Fernando Sáinz, Utilización del radio como medio educativo, de Simón Serna, Cartilla de liberación proletaria para la enseñanza de la lectura a los adultos, de Blanca Luna Islas, y Las pequeñas industrias en la escuela del campo, de Aurelio del 
Río. Los autores eran profesores en activo. Se contrastó el contenido de estos libros "prácticos y reales" con los que se habían publicado en la década de los veinte, cuando José Vasconcelos estuvo al frente de la Secretaría de Educación Pública (SEP). Se dijo entonces que los libros editados por órdenes de Vasconcelos eran para los estudiantes que aspiran a la introversión histórica y mística, no para quienes luchaban activamente por la transformación de México.

Los libros oficiales de lectura, Serie SEP y Simiente, aparecieron ya avanzado el Gobierno cardenista, entre 1937 y 1939 seguramente dificultó su distribución a tiempo, así como su cobertura nacional, principalmente en los lugares más alejados y atrasados de nuestro país para los cuales se habían hecho estos libros, especialmente los que iban dirigidos a las escuelas campesinas. Estos libros constituyeron series que iban del primero al sexto grado de primaria. Eran sencillos en su materialidad, pequeños en su tamaño y número de páginas, de pasta dura, impresos en papel común y corriente, con pocas ilustraciones en sus portadas y en su interior; las imágenes interiores eran en blanco y negro, casi de carácter lineal, las de las pastas contenían escasos colores que solo cambian dependiendo del grado, pero las imágenes eran las mismas.

En las pastas de los libros para las escuelas urbanas, ocupando planos distintos, aparece un salón de clases en cuyo pizarrón se lee Escuela Socialista, están sentados alumnos y alumnas y, al frente de pie, está una maestra; también aparecen unos obreros, un campesino y un soldado representando al ejército; recordemos que también los militares formaban parte del partido político oficial.

En las pastas de los libros para las escuelas rurales se muestra una escena al aire libre, un maestro sentado a la sombra de un árbol, con niños y niñas sentados a su alrededor. El maestro tiene un libro en una mano y con la otra señala a un campesino que ara la tierra. Desde las pastas de estos textos escolares se anuncian sus contenidos, asimismo se acentúa el peso que se le dio a la escuela, a los maestros, a los libros y a los niños en el cambio que se esperaba de la sociedad mexicana. En las pastas de ambas series aparecen niños y niñas, con esto se confirma el carácter mixto de la escuela socialista y el ataque que se hizo a las escuelas unisexuales, que eran las dominantes antes del cardenismo.

Otros títulos fueron Libérate, Serie Vida, Madre Tierra y Simiente. Su publicación causó una airada respuesta entre los obispos que no aprobaban la educación socialista. Mora (1979, p. 157) ha mostrado que además de este tipo de protestas casi no hubo otras y fueron casi excepciones las de los padres de familia, como fue el caso del Frente Único Nacional de Padres de Familia de Tamaulipas, quienes consideraban indignante ponerlos entre las manos infantiles cuando despertaban un odio contra los llamados explotadores cuando todo aquello significaba únicamente una superioridad moral o económica. Esta situación hace suponer que los maestros usaron muy poco los libros de texto en el aula o que se emplearon en zonas que no eran polémicas.

Los libros no tenían el carácter de obligatorio, no eran suficientes para la población y la demanda por parte de las instituciones particulares y escuelas públicas de las zonas urbanas se siguieron editando libros, diferentes a los oficiales, para su venta. A finales del sexenio, la SEP continuó publicando listas de libros autorizados para la educación primaria, pero como medida de control para evitar que los textos siguieran siendo fuente de lucro, se fundó la Comisión Revisora de Libros de Texto y Consulta (1940) encargada de examinar el contenido, las ilustraciones y su relación con los programas de estudio, este conjunto de libros se siguieron usando hasta finales de los años cincuenta; como ejemplo mencionamos el material educativo Camaradas, libro y cuaderno de Rosaura Lechuga, publicado en editorial Patria, fue aprobado por la Comisión Revisora y difundido en la lista del 22 de febrero de 1941 y en 1952 continuaba en el catálogo oficial. A pesar del esfuerzo gubernamental, los libros de texto siguieron siendo inaccesibles y diferentes para la mayor parte de los niños mexicanos (Meneses, 1999, pp.137, 138). 


\section{Los libros de texto único, gratuito y obligatorio}

La Comisión Nacional de Libros de Texto Gratuitos (CONALITEG) se crea por decreto presidencial el 13 de febrero de 1959, teniendo como principal acción: fijar, con apego a la metodología y a los programas respectivos, las características de los libros de texto destinados a la educación primaria (Diario Oficial, 1959). Esta iniciativa tenía como fundamento el mandato constitucional de proporcionar a los mexicanos una educación obligatoria y gratuita. La gratuidad solo sería plena cuando los alumnos de las escuelas primarias recibieran, sin costo, los libros indispensables para sus estudios y tareas (Diario Oficial, 1959).Entregar una obra escolar gratuita a los alumnos de primaria no constituía ninguna novedad. Desde el porfiriato y en los gobiernos de Álvaro Obregón, Lázaro Cárdenas y Manuel Ávila Camacho se realizaron esfuerzos para proveer de materiales de lectura y cartillas de alfabetización a las escuelas del país. La originalidad, y punto de discordia de la iniciativa, se localiza en la tríada gratuito-único-obligatorio que caracteriza hasta hoy al libro de texto gratuito y en las funciones y facultades que el Estado adquiría (Quintanilla \& Ixba, 2011).

En esta iniciativa del libro de texto no habría diferencia entre niños de escuelas primarias públicas y privadas, rurales y urbanas; cuando menos no en el material educativo que el Estado se propondría entregar. Por el carácter gratuito, único y obligatorio del libro de texto, todos los alumnos, por grados y asignaturas, recibirían los mismos impresos. Sus profesores, además, debían utilizarlos en clases y no solicitar textos comerciales excluidos del catálogo oficial de la SEP, so pena de incurrir en desacato, los profesores que incurrieran en falta podrían ser sancionados con cárcel, multa, destitución e inhabilitación para desempeñar puestos federales. En el caso de las escuelas particulares, corrían el riesgo de perder el reconocimiento oficial.

Con esta medida, la SEP, no solo unificaba contenidos, sino que se atribuía funciones de autor, editor, impresor y distribuidor e ingresaba a un mercado como un competidor insuperable, capaz de producir tirajes impresionantes, considerando que la primera entrega fue de 16 millones de ejemplares, difíciles de igualar por otras editoriales, y de llevar los libros a los rincones de un amplio territorio y, en muchos casos, de difícil acceso. Una acción que, hasta ese momento, y quizá hoy, ninguna empresa editorial había logrado.

\section{Libros de texto de la reforma educativa de los años 70}

En cuanto a los cambios en los planes de estudio, la reforma se planteaba lograr una educación integradora del alumno a su entorno social como agente de cambio responsable y auténtico. Los contenidos se orientan a hacer de él un elemento activo de su comunidad, de su estado y de su país, eliminando el concepto tradicional de educando como receptor de cultura ya elaborada (Huerta, 1976, p. 315).

Los programas para la educación primaria se orientaron hacia la comprensión de la realidad específica del alumno. Según Vargas (2011) los datos y conocimientos se enmarcaban en el momento preciso del desarrollo de la sociedad en la que se encontraba el educando, con el fin de hacerlo partícipe de ella. En esta lógica, los libros de texto gratuito tuvieron un carácter más formativo que informativo. Su elaboración fue a cargo de equipos de pedagogos y especialistas en cada área, y bajo la coordinación de directores de grado y materia. La coordinación general fue responsabilidad de la Comisión de Métodos y Planes de Estudio. La edición, publicación y distribución estuvo a cargo de la CONALITEG. El libro de texto gratuito se caracterizó por dar un giro tendiente a la modernización, pero aún dentro de una lógica desarrollista e industrialista (Vargas, 2011, p. 498).

El libro de texto gratuito de 1974 buscó promover iniciativas de apertura, popularización y flexibilización; los planes de estudio se orientaron hacia la comprensión de la realidad específica del 
alumno; la modernización y la industrialización, buscando la integración del estudiante al medio específico para conseguir la transformación social.

La estructura lógica del libro de texto gratuito, busca referir la relación contexto-alumno a través del uso cotidiano en la narrativa: se utilizan núcleos sociales micro en la explicación de hechos históricos y de actualidad; se resalta un rol activo en el educando, como ejemplo mencionamos las siguientes secciones: i) Mérida el problema del henequén, el desempleo, el turismo, la pesca y los cultivos en Yucatán; ii) La industria en Coatzacoalcos, la industria de derivación de productos del petróleo; iii) Ciudad de México el trabajo en la fábrica, llegada de gente del campo, problemas de tránsito, la lucha sindical. En cada texto es evidente el uso del recurso narrativo para presentar un nuevo contexto caracterizado por la movilización social, por el deterioro de una ideología nacionalista tendiente a la unificación y la conciliación de clases.

La primera edición del libro de Ciencias Sociales adoptó el método dialéctico y el materialismo histórico, sustentado en la tesis marxista del desarrollo histórico que interpreta todos los movimientos sociales como un necesario recurso dialéctico hacia el socialismo.

El discurso de toma de posesión de Echeverría da cuenta de este enfoque socialista:

...Nuestro tiempo desafía, en todos los países, la eficacia de la escuela. Una educación estática puede ser germen de discordia y retroceso. Hagamos de cada aula un agente dinámico del cambio social, del progreso científico y del desarrollo económico, para que sea baluarte de soberanía y fuente de patriotismo constructivo. Que surja de la escuela la nación que ambicionamos ser. Una auténtica reforma educativa exige revisar, profunda y permanentemente, los objetivos, los conceptos y las técnicas que guíen la docencia...La adquisición de patentes y el pago de regalías resultan demasiado onerosas para las estructuras económicas poco evolucionadas. El colonialismo científico agudiza las diferencias entre los países y prolonga sistemas de sujeción internacional (1970, p. 5).

\section{Libros de texto gratuito en la reforma de 1992}

El libro de texto de 1992 se publica en un contexto político de modernización de la base política y liberalización de la base económica del país. El nuevo ordenamiento de las relaciones económicas y políticas internacionales, signadas por la globalización, ponen énfasis en el intercambio comercial, científico y tecnológico y de servicios, entre los que destaca el servicio educativo, el cual enfrenta cada día la tendencia creciente a ser comparado internacionalmente, lo que exige impulsar de manera decisiva su calidad, ante el tránsito inminente de alumnos, profesores y profesionistas. En síntesis, las nuevas relaciones basadas en el modelo neoliberal, caracterizado por la apertura comercial y el achicamiento del Estado, el cual asume su ineficiencia en la interferencia con el mercado; las políticas son dirigidas específicamente a quienes están fuera de la economía de mercado sin contar con la estructura corporativista del partido. Esto marcó el inicio de la redefinición de las relaciones Estado-Sociedad, ya no a través de grupos organizados (sindicatos, obreros, campesinos) mediante de una nueva categoría: ciudadanos. La reforma educativa, dirige sus esfuerzos al tema de la excelencia. Así, el Estado promueve la evaluación y autoevaluación como estrategia para mejorar la calidad en la educación.

Los libros se centran en los siguientes problemas: la pobreza, la ecología, la democracia política y la construcción de una economía fuerte para dar trabajo y comida a todos los mexicanos (SEP, 1992 p. 76).

La estructura de este libro, en especial, cambia radicalmente en comparación con los textos anteriores, inicia su presentación con el tema "México antiguo" y termina con el apartado "Nuestras carencias", la manera de organizar los contenidos del libro de texto gratuito, a diferencia de la 
organización en retrospectiva, consigue el efecto de historia en transformación, para fortalecer la percepción de cambio y modernización social.

En el último apartado del manual La historia y tú, posterior al apartado "Nuestras carencias" se cita:

Resolver esos problemas es tarea de los mexicanos de hoy. Nuestra historia no está acabada. No se le puede poner, como en las películas, la palabra FIN. A ti te toca continuarla, como les tocó a tus padres y antepasados. Es la historia que te toca vivir y hacer, cambiar y mejorar. Es tu lugar en la historia de México (Secretaria de Educación Pública, 1992, p. 79).

Los contenidos del libro dan muestra de la correspondencia con el contexto ideológico institucional, la coincidencia de los valores del liberalismo político y el modelo de apertura económica se exaltan en los diferentes periodos históricos que registra el texto.

Se construye un proyecto en contra de los grandes nodos que se exaltan como representativos de la nación de los años pasados y exaltan el liberalismo político y el modelo económico neoliberal. Elementos de gran valor que encajan perfectamente, y esta correspondencia se exalta de manera permanente en el libro de texto gratuito. Sin embargo, y de manera inédita en comparación con los textos anteriores, la distancia que se marca con los ideales de la Revolución Mexicana se asocian con una noción fuerte de nación en proceso de transformación y modernización; donde varios de los valores históricos de la ideología revolucionaria no son vigentes ni tienen sentido en la estructura de liberalismo político y neoliberalismo económico que propone el libro de texto como referencial de la versión de nación que construye.

\section{Las reformas educativas de 2008, 2013 y 2019}

Entre los años 2006 y 2008, se realizan los siguientes sucesos: la Alianza de la Calidad Educativa, la Reforma Integral de Educación Básica; el cambio de los planes y programas de estudio (basados en un enfoque por competencias) y nuevamente la reedición de los libros de texto gratuitos de educación primaria. La reforma curricular contó con las siguientes irregularidades: violación a la norma al no publicar los programas de estudio en el Diario Oficial de la Federación (1993)de acuerdo al artículo 48 de la Ley General de Educación; no fueron consideradas las observaciones realizadas a los libros de texto gratuito de primero y sexto grados por parte de grupos de los diferentes sectores; no se tomó en cuenta la crítica que hicieron especialistas; se cancelaron las reuniones de los consejos de expertos cuya función era revisar los planes y programas de estudio; se hizo caso omiso al dictamen del Consejo Consultivo Interinstitucional de Ciencias sobre el libro de ciencias naturales de sexto año al no cumplir los requisitos mínimos para su distribución entre los alumnos.

La Alianza por la Calidad de la Educación toma el antecedente de las varias iniciativas de reforma como las siguientes: el Acuerdo Nacional para la Modernización de la Educación Básica en 1992; el Compromiso Social para la calidad de la Educación de 2002 y durante 2008 se realizaron eventos cuyo propósito era el análisis de la Reforma Integral de Educación Básica en la que participaron expertos, investigadores, maestros y padres de familia, quienes señalaron, entre otras observaciones, que se da una manipulación e ideologización de los contenidos reduciendo el tiempo dedicado a historia, geografía, cívica y ética, así como educación artística. Se mencionan graves errores de ubicación geográfica y se eliminan varias etapas de la historia en los libros de texto gratuitos de primaria, como se hizo con la Conquista y la Colonia en los nuevos volúmenes para sexto grado. En contraste se da prioridad a un enfoque que responden a una supuesta visión globalizadora: la lectura, escritura y matemáticas; con ello se estandarizan prácticas y contenidos con una visión homogénea y descontextualizada de la enseñanza y del aprendizaje. 
Los análisis concluyen que: los textos y actividades desarrollan un sujeto mecanizado, dependiente, conformista, acrítico e inmerso en un mundo globalizado, ante la homogeneización de la cultura, eliminando el interés y conocimiento del patrimonio cultural de las comunidades y su diversidad nacional. López Aguilar (2014), respecto a los libros cuestionados en 2008, plantea:

Estos libros no parten de los intereses y necesidades de los maestros y de los alumnos, los libros parecen carecer de una línea unitaria, a diferencia de las tres reformas anteriores, marcadas por el nacionalismo, el mestizaje y por una idea clara de qué tipo de ciudadanos querían los gobiernos. No llevan un proceso lógico de aprendizaje, no promueven el razonamiento, propician una baja demanda cognitiva y dificultan la generación de nuevos conocimientos en los estudiantes, causando un daño irreversible a millones de niños y jóvenes mexicanos, condenándolos a un futuro incierto y ominoso, en tanto la oligarquía económica y política culpa solo a los maestros del fracaso educativo demostrando su desprecio y falta de interés por la educación pública.

La reforma educativa de 2013 realiza una profunda revisión de los planes y programas de estudio, se elabora el denominado nuevo modelo educativo integrado por cinco ejes: i) enfoque curricular; ii) la escuela como centro del sistema educativo; iii) capacitación y desarrollo profesional de los docentes; iv) inclusión y equidad; v) gobernanza del sistema educativo. El enfoque curricular de la educación obligatoria propone tres elementos sustantivos:

1. Los campos de formación académica: Lenguaje y Comunicación; Pensamiento Matemático; Exploración y comprensión del mundo natural y social.

2. Áreas de desarrollo personal y social: Arte, Educación Socio-emocional y Educación Física.

3. Autonomía Curricular: Conocimiento regional; Proyectos de impacto social; Desarrollo personal y social; Capacitación Académica.

El nuevo modelo educativo y su planteamiento curricular reconoce la importancia de desarrollar nuevas habilidades cognitivas y sociales de los alumnos: pensamiento crítico y resolución de problemas, comunicación y colaboración, alfabetización digital y ciudadanía incluyendo las habilidades socioemocionales. Esta reforma careció de un proceso claro de planificación para su instrumentación, no existió capacitación y difusión con los docentes para garantizar el éxito del modelo; los libros de texto y los programas siguieron siendo los implementados durante los años 2010, 2011 y 2014 según al grado escolar y las áreas de estudio, se aplicó un pilotaje en algunas escuelas, cuyo resultado se desconoce. Se propuso iniciar su implementación gradualmente en el ciclo escolar 2018-2019, sin embargo, el desacierto de implementar un modelo educativo al final de la administración de un gobierno federal, queda anulada su viabilidad, considerando que los principales actores de su promoción y difusión son los docentes, los cuales se manifiestan inconformes con el sistema de evaluación punitiva implementada en la reforma educativa de 2013. Esta coyuntura, abre una propuesta al nuevo gobierno; proponer cancelar dicha reforma educativa.

En mayo de 2019 es aprobada la nueva reforma educativa y anunciado el proyecto de la Nueva Escuela Mexicana, destaca la idea de una educación regionalizada, considerando realidades económicas, geográficas sociales y culturales. La promoción formal de los estilos de vida saludables, educación sexual, la literacidad, entre otros aspectos que habrán de concretarse en los nuevos planes y programas de estudio.

Se pretende incrementar el número de escuelas de tiempo completo, crear un mecanismo para entrega eficiente y oportuna de los recursos (principalmente económicos) a las escuelas, dotarlas de servicios e infraestructura digna, además de acceso eficiente a las nuevas tecnologías. Todo esto, centrando sus esfuerzos en las zonas más desfavorecidas, pretendiendo así cumplir con el precepto de equidad educativa, entendiendo este, no como una distribución igualitaria de recursos, sino como un mecanismo para dar más a quien más lo necesita. Sin embargo, el cierre de escuelas por la 
COVID-19 ha dejado trunco el proyecto educativo de la nueva reforma educativa; los docentes están trabajando con algunos de los materiales del nuevo modelo educativo, otros lo hacen con los materiales anteriores a la reforma de 2013.

La definición e implementación de la Nueva Escuela Mexicana requiere más que rediseño de los nuevos libros de texto, como lo ha propuesto la Dirección General de Materiales Educativos. Se deben iniciar trabajos de consenso para que maestros, asesores técnicos pedagógicos, directores, supervisores, en resumen, todos los integrantes del sistema educativo; conozca los cambios a instrumentar para la Nueva Escuela Mexicana, rescatando las aportaciones de los cinco ejes del modelo educativo de la reforma de 2013.

\section{DISCUSIÓN}

Cada uno de los libros de texto de los períodos mencionados corresponde a reformas educativas que fueron parte del programa de gobierno de las respectivas administraciones con visión ideológicas diferentes. Así planteado, este trabajo pretende demostrar el vínculo entre los cambios en la sistematización de una historia nacional distintiva de cada libro de texto gratuito y las transformaciones en los proyectos de unificación nacional que se le asocian, pero que no contemplan los ciclos de su implementación en forma completa en una generación de educación básica, algunos libros de texto que tienen mayor tiempo de duración son retirados o rediseñados sin un análisis pedagógico didáctico que valore sus aciertos o propuestas de mejora.

A pesar de las innumerables reformas educativas, todos los avances en la impresión de libros, la apertura de bibliotecas en todos los centros educativos o por lo menos en algunos municipios donde se ubican diferentes escuelas, los resultados de aprendizaje de los alumnos, no son satisfactorios. Estudios recientes de las evaluaciones de rendimiento académico, principalmente para el área de lectura de comprensión, los estados de la República Mexicana, nos ubicamos en resultados debajo de la media comparativa con otros países, tenemos problemas para la retención de los alumnos de educación básica. Podemos afirmar que aún no hemos logrado la deseada educación de calidad para todos.

La lectura y la escritura son acciones que su aprendizaje se logra leyendo y escribiendo textos usados en el contexto social, los textos escolares de carácter obligatorio no son garantía para lograr un óptimo aprendizaje, es necesario reconocer e incluir textos utilizados de manera habitual en la vida social. El aprendizaje de la lectura y escritura debe incluir un repertorio variado de textos sociales y que sean objetos de interacción sistemática, tanto para ser leídos como para ser escritos. Es insustituible, por lo tanto, la presencia y disponibilidad de novelas, recetas, noticias periodísticas, cómics, anuncios publicitarios, textos expositivos, poesías, cartas, etcétera, para hojear, leer, analizar, escribir, comentar, discutir, revisar, confrontar; es decir, que sean auténticos objetos con los cuales realizar las múltiples y diversas acciones que realizamos quienes leemos y escribimos en la vida cotidiana. También en este sentido se requieren diversidad de elementos para producir textos: distintos tipos de soportes e instrumentos de escritura (Ferreiro, 1986).

Ante la propuesta, nuevamente, del rediseño de imagen de los libros de texto debemos considera que el uso de internet, la radio, la televisión y otras tantas herramientas digitales han permitido experimentar otras estrategias para la enseñanza-aprendizaje, antes de cambiar la imagen de los libros, debemos cambiar la estructura misma de los libros, sustentados en las ventajas de interacción en las redes sociales; "accesible desde internet y elaborados de acuerdo con las necesidades educativas que demanda un proceso de enseñanza-aprendizaje contextualizado" (Reynosa Navarro, 2016, p. 117).Estamos ante un cambio significativo para multiplicar los recursos para el 
aprendizaje, necesarios en la educación básica, consideremos hoy la posibilidad de que muchos estudiantes interactúan a través de las redes sociales.

¡El shock del reconocimiento! En un ambiente de información eléctrica (hoy conocida como Tecnologías de la Información y Comunicación), los grupos minoritarios ya no pueden ser contenidos-ignorados. Demasiadas personas saben demasiado las unas sobre las otras. Nuestro nuevo ambiente obliga al compromiso y a la participación. Cada uno de nosotros está ahora irrevocablemente envuelto en la vida de los demás, y es responsable de ellos (McLuhan, 1969, p. 24).

A modo de un simple ejemplo, podríamos decir que Internet extiende la capacidad de escritura, la difusión y multiplicación de contenidos, vuelve accesible la auto-publicación y garantiza las libertades de expresión y prensa; a partir de la misma, caduca a todos los medios analógicos anteriores, recupera las ventajas de la imprenta de Gutenberg, la proximidad del telégrafo, las transmisiones en vivo de la radio y la televisión, al mismo tiempo revierte y facilita el acceso a textos, noticias, contenidos diversos y homogeniza a nivel global los temas de una verdadera educación pública.

\section{CONCLUSIONES}

A lo largo de la historia de la humanidad hemos sido testigos de tres grandes inventos que han influenciado en las labores de la escolarización, el primero es la imprenta con la aparición del libro como su principal producto. El segundo la televisión, usada durante la pandemia como instrumento para la educación a distancia. El tercer el internet, con su conjunto de herramientas que han permitido modificar los modelos de interacción entre los individuos, estas últimas tecnologías han trasformado los procesos de comunicación y de acceso a la información que están por definir un nuevo modelo pedagógico en las escuelas.

Retomamos y hacemos vigentes los criterios fundamentales que estableció McLuhan (1996) para definir los medios de comunicación. Asumimos que Internet, entendido de manera general, es un medio frío. Los dos parámetros fundamentales que estableció McLuhan para realizar una diferenciación entre los medios son:

a. La definición de los datos que son transmitidos a través de los mismos.

b. El grado de participación de las audiencias para completarlos.

Así McLuhan propone el concepto de alta definición como el estado de ser bien abastecido de datos y explica:

Una caricatura es una definición baja por la sencilla razón de que proporciona muy poca información visual. Estos mediadores instrumentales son los que permiten que el aprendizaje sea significativo y no una mera recopilación memorística; es decir: aprendizaje a través de recursos simbólicos (imágenes o textos). El teléfono es un medio frío o un medio de definición baja debido a que se da al oído una cantidad mezquina de información, y el habla es un medio frío de definición baja, debido a que es muy poco lo que se da y mucho lo que el oyente tiene que completar. Los medios cálidos son de poca o baja participación, mientras que los medios fríos son de alta participación para que el público los complete.

Los medios son poderosos agentes de cambio que afectan la manera en que experimentamos el mundo, interactuamos los unos con los otros y utilizamos los sentidos físicos, los mismos sentidos que los medios extienden. Información es todo lo que está en formación, es decir, definido por su relación con otra cosa. En consecuencia: "son metáforas activas por su poder de traducir la experiencia en nuevas formas. El habla fue la primera tecnología con la que el hombre pudo soltar su entorno para volver a asirlo de una manera nueva" (McLuhan, 1996, p. 78). 
El medio es una extensión del hombre, las extensiones del hombre: la simulación tecnológica de la conciencia, por la cual los procesos creativos del conocimiento se extenderán, colectiva y corporativamente, al conjunto de la sociedad humana. Nuestras extensiones serán múltiples y diversas, hablamos más allá del cine, la televisión o los juegos de computadora, porque cualquier extensión, sea la piel, la mano o el pie afecta a todo el complejo psíquico y social.

Podemos ejemplificar con el pedal como extensión del pie, pero no solo los objetos creados por el hombre son extensiones, sino que todo evento promovido por el ser humano en la era eléctrica (era digital para nosotros), es una extensión del mismo y dentro del inventario de las principales extensiones, se encuentra la publicidad, el número, los juegos, la automatización y la palabra hablada y escrita. Como se advierte, nos encontramos ante un mundo donde han aumentado las extensiones del hombre que traen consecuencias inmediatas en nuestro ser y hacer.

Bajo esta consideración se propone que los libros de texto estén digitalizados y que su rediseño se proponga con la metodología del hipertexto, el cual se ha convertido en una forma revolucionaria de expresión, debido a sus semejanzas con las formas de proceder del cerebro humano. Durante muchos años se conoció solamente la escritura lineal, que imponía, al mismo tiempo, una forma de razonar. Con el hipertexto nos enfrentamos a una manera diferente de acceder al conocimiento, basada en la diversidad de estímulos. Esta posibilidad abre caminos insospechados a la investigación y aplicación educativas, debido a que, a diferencia de la televisión, es un sistema interactivo en el que el alumno ejercita su imaginación y creatividad, y se vuelve autogestivo (Calderoni. 1998, p. 157)

\section{REFERENCIAS}

Bajtín, M. (1997). Hacia una filosofía del acto ético (Trad. Tatiana Bubnova). Anthropos.

Calderoni, V. P. (1998) El hipertexto como nuevo recurso didáctico. Revista Latinoamericana de Estudios Educativos, XXVIII(3 y 4), 157-181. https://www.redalyc.org/pdf/270/27028407.pdf

Diario Oficial de la Federación. (Febrero 12, 1959). Decreto que crea la Comisión Nacional de Libros de Texto Gratuitos. Diario Oficial de la Federación.

Diario Oficial de la Federación. (Febrero 13, 1958) Secretaria de Educación Pública, decreto que crea la Comisión Nacional de Libros de Texto Gratuito. Diario Oficial http://www.dof.gob.mx/nota_to_imagen_fs.php?cod_diario=196156\&pagina=5\&seccion=0

Diario Oficial de la Federación (Julio 13, 1993). Ley General de Educación. Diario Oficial de la Federación. http://cgservicios.df.gob.mx/prontuario/vigente/5519.htm

Echeverría, L. (1970). Discurso de toma de protesta como presidente de México. $1^{o}$ de diciembre de 1970.http://www.biblioteca.tv/artman2/publish/1970_85/Discurso_de_Toma_de_Protesta_de_Luis_Ec heverr_a_lvarez_como_Presidente_de_los_Estados_Unidos_Mexicanos.shtml

Ferreiro, E. (1986). Proceso de alfabetización. La alfabetización en proceso. Centro Editor de América Latina.

Huerta, M. (1976). Los libros de ciencias sociales y los programas de 1972 y 1978. Secretaría de Educación Pública.

Leines, M. A. (2005) El maestro: Revista de Cultura Nacional 1921-1923. Tema y variaciones, (2), 63-86. http://zaloamati.azc.uam.mx/handle/11191/2242

López Aguilar, M. J. (Enero 18, 2014) Libros de texto gratuitos, desastre educativo. La Jornada Opinión. https://www.jornada.com.mx/2014/01/18/opinion/015a2po

Loyo, E. (1988). La lectura en México, 1920-1940 en Historia de la Lectura en México. El Colegio de México. 
Matute, Á. (1982). La lectura: el elemento fundamental. En F. Solana (coord.), Historia de la educación pública en México (pp. 177-181). FCE.

McLuhan, M. (1969). El medio es el masaje. Un inventario de efectos. Paidós.

McLuhan, M. (1996). Comprender los medios de comunicación. Las extensiones del ser humano. Paidós.

McLuhan, M., \& McLuhan, E. (1990). Las leyes de los Medios. La Nueva Ciencia. Grijalbo.

Meneses, E. (1999). Las enseñanzas de la historia de la educación en México. Universidad Iberoamericana.

Montes de Oca, E. (2007). La educación en México: Los libros oficiales de lectura editados durante el gobierno de Lázaro Cárdenas, 1934-1940. Perfiles educativos, 29(117), 111-130. http://www.scielo.org.mx/scielo.php?script=sci_arttext\&pid=S0185-

26982007000300006\&lng=es\&tlng=es

Mora, J. (1979). Los maestros y la práctica de la educación socialista. Historia Mexicana. El Colegio de México, 29(1), 133-162. https://historiamexicana.colmex.mx/index.php/RHM/article/view/2689

Quintanilla, S., \& Ixba, E. (2011). Martín Luis Guzmán y los primeros libros de texto gratuito. En La educación pública: patrimonio social de México, vol. II (pp. 143-167). FCE/SEP.

Reynosa Navarro, E. (2016). El libro de texto universitario. Un enfoque metodológico. Revista Digital De Investigación En Docencia Universitaria, 9(2), 115-126. https://doi.org/10.19083/ridu.9.415

Secretaria de Educación Pública. 1992. Mi libro de historia de México. Cuarto grado, p. 76.

Secretaria de Educación Pública.1992. Mi libro de historia de México. Cuarto grado, p, 79.

Vargas, N. (2011). La historia de México en los libros de texto gratuito: evidencia de las transformaciones en los modelos de integración nacional. Revista mexicana de investigación educativa, 16(49), 489-523. http://www.scielo.org.mx/pdf/rmie/v16n49/v16n49a8.pdf

Vasconcelos, J. (1922). Informe General de la Secretaría de Educación Pública. Exposición Internacional de Brasil. 